\title{
Clinical techniques and TeChNology
}

\section{Endoscopic adenoidectomy: a systematic analysis of outcomes and complications in 1006 patients}

\author{
Adenoidectomia endoscopica: revisione sistematica di risultati e complicanze in 1006 \\ pazienti
}

\author{
Alberto Maria Saibene ${ }^{1}$, Cecilia Rosso ${ }^{1}$, Carlotta Pipolo ${ }^{1}$, Paolo Lozza ${ }^{1}$, Alberto Scotti ${ }^{1}$, Filippo Ghelma², Fabiana Allevi ${ }^{3}$, \\ Alberto Maccari ${ }^{1}$, Giovanni Felisati ${ }^{1}$ \\ ${ }^{1}$ Otolaryngology Department, San Paolo Hospital, University of Milan, Italy; ${ }^{2}$ Disabled Advanced Medical Assistance Unit, \\ Department of Health Sciences, San Paolo Hospital, University of Milan, Italy; ${ }^{3}$ Maxillofacial Surgery Department, San Paolo \\ Hospital, University of Milan, Italy
}

\begin{abstract}
SUMMARY
Adenoid hypertrophy $(\mathrm{AH})$ is an extremely common condition in the paediatric population, relating to different pathological scenarios. Failure in responding to medical therapy often leads to adenoidectomy. While traditional adenoidectomy is indeed a relatively "blind" procedure, endoscopic procedures allow more radical resections, bleeding monitoring and complete Eustachian tube sparing, making adenoidectomy a safer, more manageable and functional procedure. Though the literature widely describes endoscopic adenoidectomy, only small case series are available and the procedure itself has never really taken hold in routine otolaryngology practice. The aim of this article is to report data on endoscopic adenoidectomy in a large single centre patient population. We retrospectively evaluated the medical records of 1006 children who underwent endoscopic adenoidectomy with or without tonsillectomy (respectively 493 and 513 patients). Data on surgical time, blood loss, hospital stay, short and long-term complications, recurrences and post-operative pain were collected. Our analysis showed that the endoscopic approach requires a longer surgical time, but it is associated with less intraoperative blood loss, a lower complication rate and less treatment failures compared to large contemporary case series of either traditional or power-assisted approaches. The overall better outcomes are more noticeable when comparing our data with classic technique case series than with power-assisted case series. Endoscopic adenoidectomy should therefore be regarded as a valid technique, which, in expert hands, lowers the rates of complications and recurrences at the expense of a slightly increased surgical time.
\end{abstract}

KEY WORDS: endoscopic adenoidectomy, power-assisted adenoidectomy, adenotonsillectomy, adenoidectomy complications

\section{RIASSUNTO}

L'ipertrofia adenoidea è una condizione estremamente comune nella popolazione pediatrica, correlata a differenti scenari patologici. Laddove la terapia medica non è sufficiente a gestire la patologia, può essere necessario ricorrere all'approccio chirurgico eseguendo un'adenoidectomia. Mentre la tecnica chirurgica tradizionale è una procedura eseguita relativamente "alla cieca", l'approccio endoscopico permette di eseguire una resezione radicale, con controllo del sanguinamento ed un completo risparmio degli osti tubarici, rendendo l'adenoidectomia video-assistita una scelta più sicura, controllata e funzionale. Nonostante in letteratura venga ampiamente descritta come tecnica, gli studi si sviluppano su piccole casistiche e l'approccio endoscopico non ha mai realmente assunto un posto centrale nella pratica otorinolaringoiatrica. Lo scopo del seguente articolo è di analizzare i risultati dell'adenoidectomia endoscopica eseguita su un'ampia popolazione di pazienti afferenti ad un unico centro. È stata eseguita un'indagine retrospettiva su un database di 1006 bambini sottoposti ad interventi di adenoidectomia endoscopica con o senza tonsillectomia (rispettivamente 513 e 493 pazienti). I dati raccolti si basano su tempo chirurgico, perdite ematiche, tempo di degenza, complicanze a breve e lungo termine, recidive e dolore post-operatorio. L'analisi ha mostrato, in confronto ad ampie casistiche di approcci sia
Received: March 8, 2019

Accepted: September 9, 2019

\section{Correspondence}

Cecilia Rosso

Otolaryngology Department, San Paolo Hospital, University of Milan, via di Rudinì 8, 20142 Milan, Italy

Fax +39 0281944704

E-mail: rosso.cecilia1@gmail.com

Funding

None.

Conflict of interest

The Authors declare no conflict of interest.

How to cite this article: Saibene AM, Rosso $\mathrm{C}$, Pipolo C, et al. Endoscopic adenoidectomy: a systematic analysis of outcomes and complications in 1006 patients. Acta Otorhinolaryngol Ital 2020;40:79-86. https://doi. org/10.14639/0392-100X-N0150

() Società Italiana di Otorinolaringoiatria e Chirurgia Cervico-Facciale

\section{(c) (1) $\Theta($}

This is an open access article distributed in accordance with the CC-BY-NC-ND (Creative Commons Attribution-NonCommercial-NoDerivatives 4.0 International) license. The article can be used by giving appropriate credit and mentioning the license, but only for non-commercial purposes and only in the original version. For further information: https:// creativecommons.org/licenses/by-nc-nd/4.0/deed.en 
tradizionali che endoscopici, un tempo chirurgico maggiore, ma allo stesso tempo minori perdite ematiche intraoperatoriamente, così come un inferiore tasso di complicanze e recidive. La differenza nei risultati è maggiormente apprezzabile comparando i nostri dati con quelli della tecnica classica piuttosto che con le casistiche su approcci endoscopici. L'adenoidectomia video-assistita dovrebbe dunque essere considerata una tecnica solida che, in mani esperte, riduce le complicanze e le recidive a spese di un maggior impiego di tempo di lavoro.

PAROLE CHIAVE: adenoidectomia endoscopica, adenoidectomia power-assisted, adenotonsillectomia, complicanze adenoidectomia

\section{Introduction}

Adenoids are a lymphoid tissue located on the nasopharyngeal posterior wall. Adenoid hypertrophy $(\mathrm{AH})$ is extremely common in the paediatric population, and usually regress spontaneously before reaching an age in the teens. Nevertheless, sometimes AH may induce a pathological condition, due to choanal space obstruction, Eustachian tube compression and/or chronic bacterial colonisation. For example, AH facilitating nasal congestion and recurrent rhinosinusitis, with long-term upper way obstruction can lead to maxillofacial growth alterations and difficulties in physical activity ${ }^{1}$. In other patients, tubaric ostium closure, with or without bacterial colonisation, may cause middle ear effusion with ear fullness or recurrent otitis media $^{2}$, with a subsequent risk in language development and communication ${ }^{3}$. Finally, AH has a definite role in snoring and sleep apnoea ${ }^{4}$.

Failure in responding to medical therapy in these pathological scenarios might lead to the need for surgical intervention ${ }^{5,6}$. Adenoidectomy is, therefore, one of the most common surgical procedures performed in the daily otolaryngological practice. Nevertheless, the development of medical technologies has also innovated surgical techniques for $\mathrm{AH}$, introducing endoscopic support for better local control and more complete resection. Traditional adenoidectomy (TA) is indeed a relatively "blind" procedure. It doesn't allow to control the surgical field, causing in turn the possibility of leaving partial adenoid tissue that can maintain the closure of Eustachian tubes or choanal obstruction; moreover, it doesn't allow to monitor bleeding points and adequately control them with selective cautery. Finally, besides major general complications related to head and neck general anaesthesia surgical procedures (i.e. airway, respiratory and cardiovascular complications) and bleeding risk, TA may determine neck stiffness, hypernasal voice and velopharyngeal insufficiency, dental trauma and Grisel syndrome ${ }^{5-8}$.

In this regard, other techniques have been constantly proposed as an evolution of TA, among which power-assisted endoscopic adenoidectomy (PEA) holds a prominent role. A transoral or transnasal endoscopic approach can improve the assessment of the rhinopharyngeal area, with thorough resections. Furthermore, endoscopy allows a closer inspection of the adenoidectomy procedure, monitoring bleeding and completely sparing the Eustachian tubes. Overall, PEA allows a safer, more manageable and functional procedure. Though PEA is widely described in scientific literature, only relatively small case series are available ${ }^{9-12}$ and the procedure itself has never really taken a hold in otolaryngological practice, with the notable exception of endoscopic adenoidectomy for cleft lip and/or palate patients ${ }^{13}$.

Many studies have already compared TA and PEA, showing how power-assisted techniques improve management of adenoidectomy in terms of pain, blood loss, recovery and surgical time, and completeness of adenoid removal, albeit in small patient cohorts ${ }^{14,15}$. On the other hand, other authors showed that, although PEA outcomes are superior to TA, subjectively no differences emerged between the two methods ${ }^{11}$, and PEA becomes the technique of choice only in specific setting such as cleft lip and palate patients ${ }^{13}$.

On this basis, and given the aforementioned literature debate, it seems important to keep developing the technique and sharing scientific evidence, especially if we take into account that adenoidectomy is performed annually in tens of thousands of children.

The aim of our paper is to provide a large single centre case series (the largest available in the literature) in a cohort of 1006 patients who underwent PEA, either with a transnasal or transoral approach. We conducted a retrospective analysis and examined indications to surgery, operative time, recovery time, pain score on a visual analogic scale (VAS) and intra/periprocedural complications such as post-operative bleeding and treatment failures. In order to provide the best reference to our evidence, our results are discussed along with the most recent and complete reviews of adenoidectomy outcomes in literature.

\section{Materials and methods}

The study was designed as a retrospective review. Due to its retrospective nature, it was granted exemption from the Internal Review Board of the San Paolo Hospital, Milan.

\section{Inclusion criteria}

- Patients aged 3 to 14 years who underwent PEA with or without tonsillectomy at the Otolaryngology Department of the Santi Paolo e Carlo Hospital in Milan, Italy, from 2007 to 2016.

- Indication to PEA following a clinical diagnosis of re- 
current upper airways infections, nasal obstruction, recurrent media otitis (AOM), chronic effusive media otitis (OME) and sleep apnoea (OSAS) not responding to adequate medical therapy (see Table I for indications to surgery).

- At least 1 year of follow-up.

\section{Exclusion criteria}

- Personal history of cleft lip and/or palate, whether surgically corrected or not.

- Personal history of previous adenotonsillectomy or adenoidectomy procedures.

\section{Study population}

From 2007 to 2016, 1132 patients consecutively underwent PEA at our institution. Among these, 1006 children were considered eligible according to our inclusion and exclusion criteria and their medical records were reviewed. 493 children underwent adenoidectomy alone, while 513 underwent adenotonsillectomy. Demographic data are reported in Table I.

Patients who underwent other procedures along with adenoidectomy or adenotonsillectomy (e.g. myringotomy, endoscopic sinus surgery, etc.) were considered eligible for the study (see Tab. I for details on additional procedures). Informed consent for surgery was obtained from both parents of each participant included.

\section{Surgical technique and patient management}

All subjects included in the study underwent adenoidectomy or adenotonsillectomy with PEA (see Tabs. I and II for data concerning the surgical procedure). All patients had preoperative complete blood count, PT, and aPTT tested. Among them, 28 showed abnormal results, 15 of whom were diagnosed with coagulation disorders on further testing, and were managed with pre- and/or postoperative medical therapy according to haematological indications. None of these patients was excluded from the case series.

Operation was performed under general anaesthesia, with orotracheal intubation. The surgical field was exposed with a McIvor mouth gag. During PEA, the soft palate was downward retracted with a 10 French intermittent PVC catheter. The procedure started with an adenoid tissue biopsy taken with a small traditional adenotome in order to provide a specimen for surgical pathology, as per our institution requirements which demand a sample of any resected tissue to be sampled and analysed. After biopsy, the PEA procedure took place: adenoidectomy was completed with a $40^{\circ}$ curved blade microdebrider introduced through the mouth, under endoscopic vision. Resection usually started along the choanal sill and proceeded downward on the posterior wall of rhinopharynx down to the inferior edge of adenoid tissue. Utmost attention was devoted to preserving the Eustachian tube. After completing the resection, haemostasis was achieved using curved bipolar forceps inserted transorally. The bipolar cautery was also performed endoscopically. PEA endoscopic vision was provided in the transoral technique by transorally introduced $4 \mathrm{~mm} 45^{\circ}$ or $70^{\circ}$ scope and by a transnasally introduced $3 \mathrm{~mm} 0^{\circ}$ scope in the transnasal technique, according to each surgeon's preference.

All the Otolaryngology Unit surgeons, both senior and junior, took part in the procedures. At least one of the senior surgeons (AMS, CP, LP, AS, AM or GF) took part in each procedure.

Planned postoperative hospital stay was 1 night for adenoidectomy patients and 2 nights for adenotonsillectomy patients.

All patients underwent intraoperative and 5-day post-surgical antibiotic prophylaxis with oral amoxicillin and clavulanic acid (70 $\mathrm{mg}$ amoxicillin/10 $\mathrm{mg}$ clavulanate/ $\mathrm{kg}$ in three daily doses) or oral clarithromycin $(15 \mathrm{mg} / \mathrm{kg}$ in two daily doses, in patients with known beta-lactam or clavulanate allergies). Furthermore, intraoperative steroid prophylaxis with dexamethasone $0.15 \mathrm{mg} / \mathrm{kg}$ was given in all children to reduce postoperative nausea and vomiting ${ }^{16}$.

Patients and parents were instructed on the same post-surgery behavioural rules (avoid exposition to hot temperatures, eat warm and soft food, restrict physical activity and practice nasal irrigations at least twice a day) for 2 weeks after surgery. Patients were also instructed to promptly report to our otolaryngology department or to our institution emergency department in case of any complication.

Otolaryngological outpatient follow-up was routinely performed 7 days after discharge, then after 3 months in association with flexible endoscopy to evaluate the completeness of the resection, and finally at 1 year after surgery for treatment success evaluation, once again re-evaluating adenoid residues with flexible endoscopy in case of treatment failure.

Clinical indications for surgery, surgical times, additional surgical procedures performed, hospital stay length, postoperative pain, completeness of adenoidectomy, treatment failures, blood loss and perioperative complications were recorded and taken into account.

For surgical time, in order to avoid any bias, we excluded patients who underwent other surgical procedures along with adenoidectomy and adenotonsillectomy. Pain was recorded for all patients using a VAS scale at 12, 24 and 48 hours after surgery. Completeness of adenoidectomy was defined as the presence of an adenoid residue no greater than a grade I according to Cohen and Konak (CK), without tubaric os- 
tium obstruction ${ }^{17}$. Intraoperative blood loss was recorded as negligible for amounts lower than $100 \mathrm{ml}$. Treatment failure was defined as the recurrence of one or more of the initially diagnosed condition at the 1-year follow-up visit.

Data were collected and elaborated in terms of descriptive statistics with Excel (Microsoft corporation, Redmond, WA, US).

\section{Results}

We recovered data on 1006 children, 578 males and 430 females, who underwent 493 surgical procedures of powerassisted adenoidectomy, and 513 of adenotonsillectomy in a 9-year period (see Tab. I). Mean age was $6.34 \pm 2.22$ years (range 3-14 years).

Clinical indications to surgical approach were classified as (see Tab. I):

- recurrent upper airways infections: main cause of adenotonsillectomy procedures (71\%) and accounting for $26 \%$ of patients requiring adenoidectomy;
- recurrent acute otitis media (OAM) or otitis media with effusion (OME): main indication for adenoidectomy surgery ( $57.8 \%$ of patients), third indication adenotonsillectomy ( $18.9 \%$ of patients);

- nasal obstruction: $36.3 \%$ of adenoidectomy indications, 9.9\% of adenotonsillectomy patients;

- obstructive sleep apnoea (OSA): $2.2 \%$ of children who underwent adenoidectomy procedures were diagnosed with OSA, while $32.9 \%$ patients with adenotonsillectomy indication were diagnosed with OSA.

We analysed surgical times, excluding patients where adenoidectomy or adenotonsillectomy were associated to other procedure (e.g. endoscopic sinus surgery, myringocentesis, biopsies, etc.). Mean surgical time for adenoidectomy was $19.24 \pm 8.61 \mathrm{~min}$, while mean time for adenotonsillectomy was $34.73 \pm 15.23 \mathrm{~min}$ (see Tab. II).

We used a VAS as a tool for recording postoperative pain. For adenoidectomy, the median VAS was 3 at 12 hours after surgery, 1 after 24 hours and 0 after 48 hours. For adenotonsillectomy procedures, we observed a median VAS

Table I. Demography, associated surgical techniques, clinical indications, surgical approach and complications in power-assisted adenoidectomy and adenotonsillectomy.

\begin{tabular}{|c|c|c|c|}
\hline Demography & Adenoidectomy & Adenotonsillectomy & Total \\
\hline Males & $270(54.8 \%)$ & $308(60 \%)$ & 578 \\
\hline Females & $223(45.2 \%)$ & 207 (40\%) & 430 \\
\hline Total & 493 & 513 & 1006 \\
\hline \multicolumn{4}{|l|}{ Associated surgery } \\
\hline Myringocentesis & $105(21.2 \%)$ & $27(5.2 \%)$ & 132 \\
\hline FESS & $8(1.6 \%)$ & $1(0.2 \%)$ & 9 \\
\hline Other surgery & $7(1.4 \%)$ & $5(1 \%)$ & 12 \\
\hline \multicolumn{4}{|l|}{ Clinical indications } \\
\hline Recurrent upper airways infections & $128(26.0 \%)$ & $364(71.0 \%)$ & 492 (48.9\%) \\
\hline Nasal obstruction & $179(36.3 \%)$ & $51(9.9 \%)$ & $230(22.8 \%)$ \\
\hline $\mathrm{AOM}-\mathrm{EOM}$ & $285(57.8 \%)$ & $97(18.9 \%)$ & $382(37.9 \%)$ \\
\hline OSA & $11(2.2 \%)$ & 169 (32.9\%) & $180(17.8 \%)$ \\
\hline \multicolumn{4}{|l|}{ Surgical approach } \\
\hline Transnasal & $112(22.7 \%)$ & $72(14.0 \%)$ & $184(18.2 \%)$ \\
\hline Transoral & $378(76.7 \%)$ & $441(86.0 \%)$ & $819(81.4 \%)$ \\
\hline \multicolumn{4}{|l|}{ Transoral approach } \\
\hline $45^{\circ}$ transoral optic & $47(9.8 \%)$ & $0(0 \%)$ & $47(5.7 \%)$ \\
\hline $70^{\circ}$ transoral optic & $341(90.2 \%)$ & $441(100 \%)$ & $782(94.3 \%)$ \\
\hline \multicolumn{4}{|l|}{ Complications } \\
\hline Self-limited epistaxis & 4 & 0 & \\
\hline Epistaxis requiring second surgery & 2 & 0 & \\
\hline Epistaxis requiring nasal packing & 4 & 0 & \\
\hline Tonsillar bleeding requiring second surgery & 0 & 4 & \\
\hline Self-limited tonsillar bleeding & 0 & 14 & \\
\hline Allergic reaction requiring ICU & 0 & 1 & \\
\hline
\end{tabular}


Table II. Results after power-assisted adenoidectomy (A) and adenotonsillectomy (AT).

\begin{tabular}{|c|c|c|c|c|c|c|c|c|c|c|}
\hline & $\begin{array}{c}\text { Intraoperative } \\
\text { time } \\
\text { (min) }\end{array}$ & SD & $\begin{array}{c}\text { Relevant } \\
\text { blood loss } \\
(>100 \mathrm{ml})\end{array}$ & $\begin{array}{c}\text { Complica } \\
\text { tions }\end{array}$ & Failures & $\begin{array}{l}\text { Recovery } \\
\text { time }\end{array}$ & $\begin{array}{l}12 \mathrm{~h} \\
\text { VAS } \\
\text { score }\end{array}$ & $\begin{array}{l}24 h \\
\text { VAS } \\
\text { score }\end{array}$ & $\begin{array}{l}48 \mathrm{~h} \\
\text { VAS } \\
\text { score }\end{array}$ & $\begin{array}{c}\text { No. } \\
\text { patients }\end{array}$ \\
\hline A & 19.24 & 8.61 & 3 & $10(2.02 \%)$ & $4(0.81 \%)$ & 1.15 & 3 & 1 & 0 & 493 \\
\hline AT & 34.73 & 15.23 & 2 & 18 (3.5\%) & $2(0.4 \%)$ & 2.06 & 4 & 2.7 & 2.5 & 513 \\
\hline
\end{tabular}

score of 4, 3 and 2, respectively, at 12, 24 and 48 hours after surgery. 7 patients who underwent adenotonsillectomy showed a 24-hour post-surgery VAS score higher than 6, requiring additional treatment with i.v. tramadol (Tab. II). Usually, patients returned to their baseline quality of life between 4 and 10 days post-operatively.

Only 3 patients showed an intraoperative blood loss higher than $100 \mathrm{ml}$ during an adenoidectomy procedure. These 3 patients reported respectively an estimated 250, 150 and $200 \mathrm{ml}$ blood loss, which did not require blood transfusions. Two patients had an intraoperative blood loss of 250 and $300 \mathrm{ml}$ during adenotonsillectomy, not requiring transfusion. All other surgeries did not result in any significant bleeding.

Mean hospitalisation time after adenoidectomy surgery was $1.15 \pm 0.52$ days and $2.06 \pm 0.45$ days after adenotonsillectomy. In both groups discharge was delayed due to uncontrolled pain, insufficient oral fluid and food intake, or complications such as bleeding (see after) or fever. After adenoidectomy, 10 patients had epistaxis (6 the same day as surgery, 3 the following day, 1 after 5 days) (Tab. II). Four of these patients required nasal packing, 4 were selflimited and 2 required revision surgery. Nine of 10 epistaxis events were anterior, and the only posterior epistaxis event was among the two requiring revision surgery. It should be noted that while all these patients underwent only an adenoidectomy procedure, most patients who underwent an associated endoscopic sinus surgery procedure had nasal packs until postoperative day 1 , reducing the overall risk of epistaxis. Among adenotonsillectomy procedures, 18 postsurgical tonsillar bleedings were recorded, only 4 of which required surgical revision. A single allergic reaction was managed conservatively in the Intensive Care Unit with corticosteroid therapy and non-invasive ventilation (see Tab. I). Further investigations on this allergic reaction did not clarify whether it could be related to antibiotic prophylaxis or to anaesthesia drugs. The allergic reaction took place after surgery was already started; therefore, the surgical team deemed it safer to complete the procedure since the patient was haemodynamically stable.

For completeness of resection evaluated 3 months after surgery, successful resection was demonstrated in $93.64 \%$ of patients. More specifically, $65.31 \%$ of patients showed complete excision, while the remaining $28.33 \%$ had residual adenoidal tissue no greater than a CK grade I. 62 patients showed a CK grade II residue and 2 children a CK grade III residue. No children with CK grade II or III belonged to the treatment failures group.

For treatment success as evaluated at 1-year postoperative follow-up, after adenoidectomy 4 patients showed persistent nasal obstruction. After adenotonsillectomy, 1 patient reported persistent recurrent pharyngitis, while another reported persistence of sleep apnoea (Tab. II). These 5 patients were further evaluated during the 1-year visit with flexible endoscopy, which documented no residual adenoid hypertrophy.

Overall, short-term complications after power-assisted adenoidectomy were recorded in $2.02 \%$ of patients, and in $3.6 \%$ of patients after endoscopic adenotonsillectomy. Treatment failures rate were $1.01 \%$ for adenoidectomy and $0.38 \%$ for adenotonsillectomy. None of these patients belonged to the coagulation disorder group.

\section{Discussion}

Adenoidectomy is not only the most common procedure in paediatric otolaryngology, but also, from a general standpoint, one of the most frequently performed surgical procedures worldwide. Even if relatively unchanged over time, the TA technique may result in well-known and widely described side effects and complications. Being a relatively "blind" technique, TA does not allow complete surgical field vision, possibly leading to a tubaric ostia damage, incomplete adenoid removal causing disease recurrence and uncontrolled bleeding ${ }^{15,18}$. On the other hand, TA is an established technique, with an overall low rate of complications, negligible costs and negligible operative times ${ }^{4}$.

The introduction of PEA in the early nineties was the only relevant threat posed to the historical predominance of the classic technique. PEA employs transoral or transnasal rigid scopes, providing a complete view of the surgical field with undoubtedly better local control, generally at the expense of a longer procedural time ${ }^{9}$.

Many studies have compared TA and PEA in order to shed some light on the advantages of this somewhat innovative procedure, but no study succeeded in providing analytic 
data over a considerable case load. For example, many authors reported analytic data on procedural times in TA in wide case series ${ }^{11,14,15,18-22}$. On the other hand, data concerning procedural times in PEA are available only in selected case series, ranging from 10 to 100 patients, reporting conflicting conclusions. For example, according to some authors such as Öztürk ${ }^{20}$, Stanislaw ${ }^{15}$, Anand ${ }^{14}$ and AlMazrou ${ }^{18}$, PEA shortens operative times, while other studies indicate a longer mean surgical time than TA. Datta ${ }^{21}$ and Hussein ${ }^{22}$ reported mean operative times of 42.75 and $39.3 \mathrm{~min}$, respectively, both in case series in which PEA was used during adenotonsillectomy procedures.

In order to provide a references in terms of mean intraoperative time, bleeding, short and long-term complications and treatment failures, we summarised the results of 8 solid trials comparing TA and PEA in Table III 11,14,15,18-22. Regarding procedural times, in our case series PEA per- formed worse than literature reports on TA. PEA has known longer operative times, although it has to be noted that some authors ${ }^{11}$ correctly emphasised that the overall time spent in the operating theatre is more relevant than the procedural time itself. Furthermore, it has to be noted that even literature reports on TA shows highly variable procedural times, which can be explained by analysing other variables in depth, e.g. choice on whether to apply cautery or not ${ }^{11,22}$.

Bleeding is another critical point in surgical management. The literature reports that, obviously enough, during PEA, mean blood loss values are significantly lower for isolated adenoidectomy ${ }^{14,15,18}$ than in adenotonsillectomy ${ }^{11,21}$. Interestingly, our case series shows slightly different results, with a smaller difference in terms of bleeding between isolated endoscopic adenoidectomy and adenotonsillectomy. Three adenoidectomy procedures registered blood losses

Table III. Results in literatures for traditional (TA) and power-assisted endoscopic adenoidectomy (PEA) in terms of intraoperative time, blood loss, complications, recurrences and overall outcomes.

\begin{tabular}{|c|c|c|c|c|c|c|c|}
\hline Mean values & Technique & $\begin{array}{l}\text { Intraoperative time } \\
\text { (min) }\end{array}$ & $\begin{array}{l}\text { Blood loss } \\
\quad(\mathrm{ml})\end{array}$ & Complications & Failures & Total & Surgery \\
\hline \multicolumn{8}{|l|}{ Murray ${ }^{19}$} \\
\hline & TA & 8.08 & 48 & 0 & 0 & 40 & $A$ \\
\hline \multicolumn{8}{|l|}{ Songu ${ }^{11}$} \\
\hline & TA & 7.15 & 22.9 & - & $3(3 \%)$ & 10 & $A \pm T$ \\
\hline & PEA & 12.02 & 26.3 & - & $1(0.5 \%)$ & 20 & $A \pm T$ \\
\hline & TA & 16.5 & - & $2(7.6 \%)$ & 0 & 26 & $A$ \\
\hline & PEA & 11.8 & - & $1(3.7 \%)$ & 0 & 27 & $A$ \\
\hline \multicolumn{8}{|l|}{ Stanislaw ${ }^{15}$} \\
\hline & TA & 12.5 & 24 & $1(1.1 \%)$ & $8(9.1 \%)$ & 87 & $A$ \\
\hline & PEA & 10.1 & 17.5 & $1(1.1 \%)$ & $1(1.1 \%)$ & 90 & $A$ \\
\hline \multicolumn{8}{|l|}{ Al-Mazrou ${ }^{18}$} \\
\hline & TA & 12.3 & 22.1 & $4(28.5 \%)$ & $7(50 \%)$ & 14 & $A$ \\
\hline & PEA & 6.2 & 8.2 & $3(11.5 \%)$ & $1(3.8 \%)$ & 26 & A \\
\hline \multicolumn{8}{|l|}{ Hussein 22} \\
\hline & TA & 32.25 & - & $3(15 \%)$ & $4(20 \%)$ & 20 & $A \pm T$ \\
\hline & PEA & 42.75 & - & $5(25 \%)$ & 0 & 20 & $A \pm T$ \\
\hline \multicolumn{8}{|l|}{ Datta ${ }^{21}$} \\
\hline & TA & 29.3 & 21 & $5(16.6 \%)$ & $16(53.3 \%)$ & 30 & $A \pm T$ \\
\hline & PEA & 39.3 & 31 & $3(10 \%)$ & 0 & 30 & $A \pm T$ \\
\hline
\end{tabular}

A: adenoidectomy; T: tonsillectomy. 
over $100 \mathrm{ml}(0.6 \%)$, compared to only 2 adenotonsillectomy procedures $(0.38 \%)$. Nevertheless, this difference can be ascribed to a random variation in our patients, considering the overall extremely reduced blood loss in these procedures.

Complications after TA were reported as ranging from $28.5 \%$ (Al-Mazrou ${ }^{18}$ ) to 0 (Murray et al. ${ }^{19}$ ), while PEA showed a lower complication rates ranging from $25 \%$ (AlMazrou ${ }^{18}$ ) to $1.1 \%$ (Stanislaw ${ }^{15}$ ). In our case series, complications were described in $2.0 \%$ of patients undergoing adenoidectomy, and in 3.5\% of patients undergoing adenotonsillectomy. Though PEA performs better than most literature reports on TA, it is interesting though how selected TA case series with low complication rates ${ }^{19}$ did not differ significantly from our case series. When comparing our rate of complications with other PEA literature reports, ours is comparable only to studies including at least 90 patients ${ }^{15}$. This decrease in complications rate in larger case series may be the results of more solid surgical experience in the technique. Nevertheless, in our experience, PEA showed a shallow learning curve, with younger specialists getting a swift hold on the technique, both in terms of surgical times and complication rates.

Recurrences after adenoidectomy surgery are common, as can be seen in the literature with Emerick ${ }^{24}$. In our study, treatment failure rates were $0.81 \%$ after adenoidectomy and $0.4 \%$ after adenotonsillectomy. It has to be noted though that $6.4 \%$ of patients in our study showed a 1 -year CK class II-III adenoidal residue, which was not linked to treatment failure. Our results did not significantly differ from literature reports, where treatment failures rate for PEA range from 0 to $3.8 \%$. TA shows higher failure rates, which range from 0 to $53 \%{ }^{14,15,19-22}$. Both our data and literature reports therefore suggest that while PEA may be inconvenient in terms of time management, it is associated with greater accuracy and predictability of results.

Since none of the aforementioned randomised controlled trials included relevant data on pain, we chose to compare our data with the VAS score reported by Vons et al. ${ }^{23}$ in a cohort of patients treated with TA. Vons et al. ${ }^{23}$ recorded pain intensity after day-surgery adenoidectomy and adenotonsillectomy both in hospital and during 1-week follow-up period. Patients were discharged with a median VAS score of 1 after adenoidectomy and 2 after adenotonsillectomy; the score increased at the first measurement at home to 2 for adenoidectomy and 4.5 for adenotonsillectomy procedure. At 48 hours after surgery, a score of 0 points was reported in patients who underwent adenoidectomy surgery, and 3 after adenotonsillectomy. Our data based on the VAS measurement of pain did not significantly differ from that reported in the aforementioned study. It has to be noted that our case series has two major differences in management compared to other studies cited herein, namely patient discharge and antibiotic prophylaxis. For example, many authors proposed PEA as an outpatient procedure ${ }^{15,20,23,25}$. They performed outpatient surgery with day care treatment, followed by 7-day post-operative control or in some cases just by phone call ${ }^{15}$. In our unit, we prefer to maintain at least a 1-day observation after adenoidectomy and 2 days after adenotonsillectomy, to ensure an adequate successful monitoring, which could have positively affected our complication rate, albeit with obviously higher healthcarerelated costs. The second major difference is the broad use in our case series of antibiotic prophylaxis, which is not endorsed by any specific guideline. Widespread use of intraoperative and postoperative antibiotic prophylaxis is a matter of debate and, while it may reduce the risk of infection and patient readmission, therefore lowering the complication rate, it can show detrimental effects on inducing antibiotic resistances.

While our work provides interesting insight on a wide single-centre case series, a major drawback when comparing our data with other recent studies is the lack of a control group of patients treated with other techniques. Such lack of comparison is due to our institutional choice to provide PEA to all paediatric patients, which we consider the most reliable technique, but undoubtedly weakens our findings.

\section{Conclusions}

Power-assisted adenoidectomy provides safer and more controlled surgical options, in terms of bleeding, shortterm and long-term complications and therapeutic failures. In our view, our large case series of 1006 patients definitely confirms those findings, justifying a slightly longer intraoperative time in exchange for overall better outcomes, with an even more significant impact on surgical practice due to the number of patients who will undergo this procedure on a daily basis.

\section{References}

Zicari AM, Rugiano A, Ragusa G, et al. The evaluation of adenoid hypertrophy and obstruction grading based on rhinomanometry after nasal decongestant test in children. Eur Rev Med Pharmacol Sci 2013;17:2962-7. http://www.ncbi.nlm.nih.gov/pubmed/24254568. Accessed September 1, 2018

2 Liu W, Zhang S, Zhang Y, et al. [The correlation studies between recurrent otitis media and adenoid hypertrophy in children]. Lin Chung Er Bi Yan Hou Tou Jing Wai Ke Za Zhi 2013;27:722-5. http://www. ncbi.nlm.nih.gov/pubmed/24073583. Accessed September 1, 2018.

3 Soylu E, Soylu N, Polat C, et al. Developmental delays in preschool children with adenotonsillar hypertrophy. Kulak Burun Bogaz Ihtis Derg 2016;26:129-34. htpps://doi.org/10.5606/kbbihtisas.2016.42724

4 Shen L, Lin Z, Xu Y, et al. [The relationship between obstructive 
sleep apnea hypopnea syndrome and adenoid size as well as tonsil size in children]. Lin Chung Er Bi Yan Hou Tou Jing Wai Ke Za Zhi 2014;28:381-5. http://www.ncbi.nlm.nih.gov/pubmed/24961124. Accessed September 1, 2018.

5 Yang L, Shan Y, Wang S, et al. Endoscopic assisted adenoidectomy versus conventional curettage adenoidectomy: a meta-analysis of randomized controlled trials. Springerplus 2016;5:426. https://doi. org/10.1186/s40064-016-2072-1

6 Amoils M, Chang KW, Saynina O, et al. Postoperative complications in pediatric tonsillectomy and adenoidectomy in ambulatory vs inpatient settings. JAMA Otolaryngol Head Neck Surg 2016;142:344-50. https://doi.org/10.1001/jamaoto.2015.3634

7 Abdel-Aziz M, Dewidar H, El-Hoshy H, et al. Treatment of persistent post-adenoidectomy velopharyngeal insufficiency by sphincter pharyngoplasty. Int J Pediatr Otorhinolaryngol 2009;73:1329-33. https:// doi.org/10.1016/j.ijporl.2009.05.026

8 Miller BJ, Lakhani R, Rashid A, et al. Painful torticollis following adenotonsillectomy: a cardinal sign of atlantoaxial subluxation. BMJ Case Rep 2018;2018. https://doi.org/10.1136/bcr-2017-223567

9 Costantini F, Salamanca F, Amaina T, et al. Videoendoscopic adenoidectomy with microdebrider. Acta Otorhinolaryngol Ital 2008;28:26-9.

10 Kumar A, Cascarini L, Mccaul JA, et al. How should we manage oral leukoplakia? Br J Oral Maxillofac Surg 2013;51:377-83. https://doi. org/10.1016/j.bjoms.2012.10.018

11 Songu M, Altay C, Adibelli ZH, et al. Endoscopic-assisted versus curettage adenoidectomy: a prospective, randomized, double-blind study with objective outcome measures. Laryngoscope 2010;120:1895-9. https://doi.org/10.1002/lary.21045

12 Williams H, Grounds RO, Smith B, et al. Power-assisted endoscopic adenoidectomy using a $120^{\circ}$ reverse-viewing telescope. https://doi. org/10.1308/rcsann.2015.0054

13 Abdel-Aziz M, Khalifa B, Shawky A, et al. Trans-oral endoscopic partial adenoidectomy does not worsen the speech after cleft palate repair. Braz J Otorhinolaryngol 2016;82:422-6. https://doi. org/10.1016/j.bjorl.2015.08.025

14 Anand V, Sarin V, Singh B. Changing trends in adenoidectomy. Indian J Otolaryngol Head Neck Surg 2014;66:375-80. https://doi. org/10.1007/s12070-013-0698-7
15 Stanislaw P, Koltai PJ, Feustel PJ, et al. Comparison of power-assisted adenoidectomy vs adenoid curette adenoidectomy. Arch Otolaryngol Head Neck Surg 2000;126:845-9. https://doi.org/:10.1001/archotol.126.7.845

16 Frelich M, Divák J, Vodička V, et al. Dexamethasone reduces the in cidence of postoperative nausea and vomiting in children undergoing endoscopic adenoidectomy under general anesthesia without increasing the risk of postoperative hemorrhage. Med Sci Monit 2018;24:8430-8. https://doi.org/10.12659/MSM.911231

17 Cohen D, Konak S. The evaluation of radiographs of the nasopharynx. Clin Otolaryngol Allied Sci 1985;10:73-8. https://doi. org/10.1111/j.1365-2273.1985.tb01170.x

18 Al-Mazrou KA, Al-Qahtani A, Al-Fayez AI. Effectiveness of transnasal endoscopic powered adenoidectomy in patients with choanal adenoids. Int J Pediatr Otorhinolaryngol 2009;73:1650-2. https://doi. org/10.1016/J.IJPORL.2009.08.019

19 Murray N, Fitzpatrick P, Guarisco JL. Powered partial adenoidectomy. Arch Otolaryngol Neck Surg 2002;128:792-6. https://doi. org/10.1001/archotol.128.7.792

20 Öztürk Ö, Polat S. Comparison of transoral power-assisted endoscopic adenoidectomy to curettage adenoidectomy. Adv Ther 2012;29:70821. https://doi.org/10.1007/s12325-012-0036-6

21 Datta R, Singh VP, Deshpal. Conventional versus endoscopic powered adenoidectomy: a comparative study. Med J Armed Forces India 2009;65:308-12. https://doi.org/10.1016/S0377-1237(09)80089-0

22 Hussein IA, AL-Juboori S. Conventional versus endoscopic-assisted adenoidectomy: a comparative study. Med J Babylon 2012;9:570-82.

23 Vons KMJ, Bijker JB, Verwijs EW, et al. Postoperative pain during the first week after adenoidectomy and guillotine adenotonsillectomy in children. Pediatr Anesth 2014;24:476-82. https://doi.org/10.1111/ pan. 12383

24 Emerick KS, Cunningham MJ. Tubal tonsil hypertrophy. Arch Otolaryngol Head Neck Surg 2006;132:153-6. https://doi.org/10.1001/ archotol.132.2.153

25 Rose JB, Cuy R, Cohen DE, et al. Preoperative oral dextromethorphan does not reduce pain or analgesic consumption in children after adenotonsillectomy. Anesth Analg 1999;88:749-53. https://doi. org/10.1097/00000539-199904000-00012 